\title{
VYGOTSKI E SARTRE: APROXIMANDO CONCEPÇÕES METODOLÓGICAS NA CONSTRUÇÃO DO SABER PSICOLÓGICO
}

\author{
Kátia Maheirie \\ Universidade Federal de Santa Catarina, Florianópolis, Brasil \\ Kelly Bedin França
}

\begin{abstract}
RESUMO: Para apontar contribuições metodológicas de Sartre e Vygotski à Psicologia, este artigo recupera as obras: "O significado histórico da crise da psicologia. Uma investigação metodológica" (Vygotski, 1996) e "Questão de método" (Sartre, 1960/1987). Em seu texto, Vygotski identifica uma crise na Psicologia daquele tempo, indicando sua superação por uma abordagem metodológica calcada nas reflexões de Marx. Também Sartre retorna aos escritos marxianos, visando o sujeito como singularidade irredutível que se constitui nas relações sociais. Finalmente, Sartre e Vygotski defendem posturas metodológicas que abarquem, simultaneamente, o sujeito ímpar e a totalização histórica inacabada em que se faz. Cada autor, a sua maneira, advoga a especificidade que caracteriza o humano, concebendo a subjetividade na relação com a objetividade, num movimento dialético incessante. Entendendo o sujeito como produto e produtor da cultura, os autores podem colaborar para uma psicologia comprometida com seu contexto político, porque orientada por uma perspectiva de transformação social.
\end{abstract}

PALAVRAS CHAVE: Vygotski e Sartre; método; Psicologia Histórico-Dialética.

\section{VYGOTSKY AND SARTRE: APPROACHING METHODOLOGICAL CONCEPTIONS IN THE CONSTRUCTION OF PSYCHOLOGICAL KNOWLEDGE}

\begin{abstract}
This article aims to point out Vygotsky's and Sartre's methodological contributions to psychology, using the following literature: "O significado histórico da crise da psicologia. Uma investigação metodológica" (Vygotsky, 1996) and "Questão de Método" (Sartre, 1987). Vygotsky identifies a psychological crisis, indicating that to overcome it depends on a methodological approach based on Marx's thoughts. Sartre also returns to Marx's writings, to define the subject as an irreducible singularity which is constituted on social relations. Finally, Sartre and Vygotsky share a methodological position which comprehends, simultaneously, the singularity of human beings and its unfinished historical totalizing process. Each author, in his own way, assumes specificities that characterize the human being, conceiving subjectivity in an incessant and dialectic relation with objectivity. Understanding the subject as a product and producer of culture, the authors can collaborate for a psychology engaged within its political context, from the perspective of social transformation.
\end{abstract}

KEYWORDS: Vygotsky and Sartre; method; historical-dialetical psychology.

Este trabalho visa expor e aproximar as teorizações de Sartre e Vygotski, tomando como foco de análise suas concepções metodológicas, fundamentalmente a partir dos textos "O significado histórico da crise da psicologia. Uma investigação metodológica" (Vygotski, ${ }^{1}$ 1927/1991) e "Questão de método" (Sartre, 1960/1987). A fim de localizar este artigo no conjunto do que vem sendo produzido no campo da psicologia, procedeu-se a um levantamento no Banco de Teses ${ }^{2}$ mantido pela Capes, bem como na biblioteca eletrônica SciELO, ${ }^{3}$ lançando os termos "Sartre" "Vygotski", simultaneamente. A pesquisa retornou 4 trabalhos: ${ }^{4} \mathrm{em}$ dois deles (Oliveira, M., 1998; Oliveira, P., 2004), são utilizadas as contribuiçõos específicas de Sartre acerca da teoria literária, que é articulada às teorizações de outros autores, dentre eles, Vygotski. Já os trabalhos de Maheirie $(2001,2003)$, propõem-se a estabelecer o diálogo entre as concepções sartreana e vygotskiana, para uma compreensão dos processos de criação humanos.
Concordando com Maheirie (2003), que sinaliza a semelhança entre as visões antropológicas de Sartre e Vygotski, vale ressaltar que suas diferenças se inscrevem em um campo que se pauta no ontológico. Sartre formula sua proposta a partir da leitura crítica que faz do existencialismo de Kierkegaard, apropriando-se da noção de "vivência" como ontologicamente anterior à esfera do reflexivo (Sartre, 1960/1987), aliando-a a noção de consciência como relação (intencionalidade), ${ }^{5}$ apropriação crítica que faz da fenomenologia de Husserl (Sartre, 1943/1997). Já trabalhando com estas duas correntes filosóficas, Sartre encontra o marxismo, o qual julga ser um sistema filosófico de grande importância na história da filosofia, considerando-o insuperável do ponto de vista antropológico. No entanto, critica algumas apropriações mecanicistas que alguns marxistas fizeram da obra de Marx, perdendo o caráter humano dos processos históricos e do seu movimento dialético. Vygotski, por sua vez, não se apropria 
daquelas duas correntes filosóficas, ficando como uma de suas maiores influências, além de Marx, a concepção ontológica de Spinoza.

Não obstante suas diferenças ontológicas, este artigo visa pontuar aproximações entre as elaborações de Vygotski e Sartre, considerando que a discussão metodológica é um elemento significativo para uma reflexão crítica acerca do fazer psicológico. Nesse sentido, almeja-se pôr em relevo as teorizações de dois autores que, apesar de suas dissonâncias filosóficas, podem contribuir para a constituição de uma psicologia comprometida com seu contexto político, porque orientada por uma perspectiva de transformação social.

\section{A Defesa da Especificidade Cultural do Humano}

Vygotski (1896-1934), no texto alvo de atenção deste artigo (Vygotski,1996), focaliza seu olhar naquilo que identificava como ambigüidades gravitando em torno da psicologia, indicando a presença de uma crise nesse campo de saber científico. Mapeando tal crise, Vygotski enfatiza as profundas distinções entre os sistemas teóricos de destaque daquele tempo - Psicanálise, Behaviorismo e a Psicologia Subjetiva $^{6}$-, os quais definiam três objetos de análise distintos. Postulando, respectivamente, o inconsciente, o comportamento, e o psíquico acessado pela introspecção, essas teorias se faziam irredutíveis umas às outras, não tendo em vista o mesmo objeto e implicando em conceitos que não podiam ser generalizáveis para todo o campo da psicologia.

Mantendo como fio condutor uma perspectiva histórica de abordagem da ciência psicológica, Vygotski (1996) defende que, considerando o conhecimento produzido até aquele período, os sistemas teóricos existentes poderiam ser agrupados em apenas "duas Psicologias". Uma delas percorria uma trajetória descritiva, espiritualista e idealista, em contraposição ao caminho explicativo, materialista e científico tomado pela outra vertente. $\mathrm{O}$ autor pondera que, se a exigência de uma perspectiva metodológica científica partia justamente das necessidades da Psicologia Aplicada, ${ }^{7}$ a via idealista não possibilitaria a superação da crise na/da psicologia. Para ele, isso indica que a construção de uma Psicologia Científica requer a escolha do materialismo histórico e a dialética. A construção de uma Psicologia Científica, portanto, passa pela escolha da abordagem materialista.

Vygotski (1996) destaca que existem algumas escolas que discordavam desta sua posição, as quais acreditavam superar, através de uma "terceira via", a oposição entre o empirismo e o comportamentalismo. Vygotski enfatiza, neste contexto, a teoria da Gestalt, o personalismo de Stern e a Psicologia Marxista nascente.

Um estudo aprofundado destas propostas põe às claras, de acordo com Vygotski (1996), que elas acabavam por recair, cada uma a sua maneira, num dos pólos que supõem transcender. Segundo ele, enquanto a primeira resvalava para o extremo natural-materialista, a segunda se inclinava para o idealismo. A Psicologia Marxista daquele tempo, representada, dentre outros, por Kornílov e Tchelpánov, caracterizava para Vygotski, um conjunto de tentativas trôpegas de buscar já em Marx e Engels reflexões psicológicas, desejando uma ciência pronta antes mesmo de desenvolvê-la - o que revelava falta de clareza acerca do papel histórico da própria psicologia. Dessa feita, Vygotski propõe retomar a obra "O Capital", de Marx, não pelas citações ou pela repetição do marxismo, mas para buscar aí o método.

Vygotski (1996) salienta que essa concepção viabiliza deslindar um aspecto central para o entendimento e ultrapassagem da crise do campo psicológico, qual seja, a delimitação e diferenciação entre questões gnoseológicas e ontológicas. O autor assevera que havia estudiosos os quais superpunham a "consciência gnoseológica", enquanto sujeito que se relaciona com o objeto no processo de produzir conhecimento, à "consciência ${ }^{8}$ psicológica" ou "empírica”.

Isso porque, se nas ciências naturais é gritante a diferença entre o fenômeno estudado e a consciência que visa apreendê-lo, na psicologia, o fato de o sujeito-pesquisador se propor a investigar justamente o psíquico, acaba por trazer, em algumas perspectivas, uma confusão que mescla a vivência, ao objeto de estudo. Vygotski (1996) retoma Engels para sustentar essa posição, afirmando que, se é possível ao ser humano estudar a visão das formigas sem ter acesso ao modo como o enxergar para elas se processa, também os fenômenos psíquicos podem ser investigados através de uma metodologia objetiva, sem recorrer à descrição introspectiva do sujeito.

Ainda contrapondo-se aos defensores da introspecção, Vygotski explicita que, num processo de pensamento, um sujeito pode tomar a si mesmo como objeto de reflexão. Nesse movimento, o psíquico se desdobra em sujeito e objeto. $\mathrm{O}$ autor advoga, portanto, que uma psicologia objetiva só é possível ao passo em que diferenciar sensação e conhecimento, distinguindo a consciência, do estudo da consciência, pois se assim não fosse, "cada homem seria psicólogo-cientista e a ciência seria impossível, só seria possível o registro" (Vygotski, 1996, p. 384).

Em outra passagem, o autor russo insiste igualmente nessas demarcações, para enfatizar a importância de um método que, para além da experiência direta, seja via indireta de investigação. Segundo Vygotski, um instrumento como o termômetro, não é simplesmente ampliador do tato humano, posto que apreende o real de uma maneira específica e delimitada. Assim, ao invés de aprofundar a sensação, é ferramenta que implica na produção dos conhecimentos de maneira mediada, pois é preciso que o sujeito 
interprete aquilo que se lhe oferece através deste recurso. Vygotski compreende o método como a lente que possibilita ao sujeito fazer ciência, afirmando que "um olho que tudo visse, precisamente por isto nada veria" (Vygotski, 1996, p. 284).

Em verdade, a percepção humana possui limites e possibilidades que tem a ver com a estrutura física dos órgãos dos sentidos que se formam num dado contexto social. Como um exemplo, compreende-se que um sujeito é capaz de perceber a cor vermelha, imbuída de determinados significados compartilhados coletivamente e sentidos singulares, mas não consegue enxergar um micróbio. Portanto, a percepção não está diretamente relacionada à sobrevivência biológica, sendo culturalmente construída de forma a habilitar o sujeito a selecionar e organizar os estímulos. Nesta direção, os métodos indiretos de investigação científica se fazem fundamentais, como uma necessidade do processo mesmo do conhecimento humano. Superar a percepção imediata, permite, por exemplo, que se compreenda que é a Terra que gira ao redor do Sol, a despeito das aparências sugerirem o inverso.

Vygotski (1996) assevera que, em seu tratado sobre a Psicologia da Arte, buscou levar ao cabo tal método indireto. Nesse sentido, para compreender os efeitos da relação do sujeito com a arte, Vygotski rompe com as abordagens que focavam ora no psiquismo singular, ora na psicologia dos personagens da obra, fosse ela uma representação teatral, ou um romance. A partir do estudo do objeto estético, atentando para a configuração material peculiar entre forma e conteúdo produzida pelo artista, Vygotski pôde compreender a vivência estética, enquanto apropriação específica que o sujeito faz de uma obra de arte (Vygotski, 1925/1998, 1926/2001). Esta investigação indireta, porque visa entender a produção de novos sentidos pelo fruidor da obra de arte com o apoio da análise da estrutura do objeto, institui um método "analítico-objetivo" (Vygotski, 1996, p. 372), que extrai do estudo da obra elementos que diferenciam a vivência estética das demais, garantindo sua especificidade. Neste caso, a arte é concebida como produto social, objetivação ímpar de um artista que se faz num contexto e, simultaneamente "técnica social do sentimento" (Vygotski, 1925/1998), ou seja, instrumento por meio do qual cada sujeito singular se apropria da cultura. Assim, com o estudo das relações entre arte e sociedade, Vygotski exemplifica os princípios metodológicos necessários para constituir uma ciência psicológica calcada numa concepção filosófica que possibilite ver cada sujeito como partícipe ativo da construção da história, ao mesmo tempo em que é coletivamente constituído, condensando em si, de forma complexa, as relações sociais.

Retomando a discussão vygotskiana acerca da crise na psicologia, vale destacar que o autor define toda e qualquer ciência, enquanto atividade humana, como relação entre a pessoa e o mundo: o conhecimento é determinado tanto pelo objeto, quanto pelo sujeito que se propõe a conhecê-lo. Por um lado, o conhecer depende das possibilidades cognitivas do sujeito num determinado momento histórico. Por outro lado, o objeto do estudo científico é da ordem da significação. Logo, é a inserção de qualquer elemento do mundo, numa determinada relação entre signos que, articulados entre si, conformam um sistema teórico, que confere a qualquer objeto o caráter de científico.

Assim, a ciência não é esqueleto, ossatura morta, mas um tecido vivo, já que, a cada movimento de aproximação dos conceitos a uma dada realidade, é preciso reconfigurá-los, estabelecer entre eles novas relações, tendo como norte as exigências da prática. A mútua constituição entre conceitos e objetos científicos garante à ciência constantes modificações. Sob esse prisma, a linguagem ganha destaque na produção de conhecimento científico. Como a percepção dos objetos é inseparável da sua nomeação e classificação, demandando processos de pensamento, cada palavra que o pesquisador utiliza acaba por condensar em si uma postura metodológica.

Atento ao movimento revolucionário de seu tempo, Vygotski finaliza seu texto situando a Psicologia Geral Dialética por ele proposta num lugar de destaque no futuro, pois acreditava que para o exercício da liberdade são fundamentais as questões e teorizações que remetem aos processos de auto-regulação dos sujeitos. Interessante destacar que a reflexão vygotskiana acerca da autonomia, por meio da investigação sobre os processos psicológicos complexos, se faz presente, já no ano de 1931, em outro texto também dedicado à discussão metodológica.

Nesse trabalho, "Método de investigación" (Vygotski, 1931/1995, p. 47-96), o autor russo critica os experimentos realizados em psicologia até então, considerando que eles "animalizavam" os sujeitos, por assim dizer. Tais pesquisas, para ele, revelavam um desconhecimento das diferenças fundamentais entre processos elementares, calcados em mecanismos psicofisiológicos (que se caracterizam pela relação linear entre estímulo e resposta) e processos complexos, como, por exemplo, a linguagem. Vygotski afirma que esses estudos acabavam por confundir o que os seres humanos compartilham com os animais e aquilo que lhes é específico: precisamente o que se produz em seu desenvolvimento cultural. Para Vygotski, tal equívoco implica negligenciar os modos de atividade constituídos na história da humanidade através do trabalho humano sobre a natureza, que assumem a forma de relação ativa com o meio - contrapondo-se ao modo passivo de relação dos animais. Perde-se aí o papel fundante da vida social na formação dos processos psicológicos pelos quais o ser humano aprende a auto-regular sua conduta.

Por conseguinte, a Psicologia Geral proposta por Vygotski, é inextricavelmente histórica, e deve debruçar-se 
sobre o homem naquilo que lhe é peculiar, resgatando uma visão humanizadora do sujeito. Desse ponto de vista, o autor russo se destaca pela ênfase no caráter criador do ser humano, que produz cultura e nesse processo, produz a si mesmo, para além do biológico. A ciência psicológica, para apreender esses movimentos, precisa assumir, enquanto método, uma perspectiva dialética e histórica, compreendendo que o conhecimento se constitui na relação do sujeito com o objeto, a qual depende da mediação do outro e, portanto, da linguagem, num contexto social específico.

\section{A Compreensão da Singularidade que se faz num Contexto Social e Histórico}

Sartre (1905-1980), a pedido de um periódico polonês, no ano de 1957, escreve um texto com o objetivo de comentar a situação do existencialismo naquele período. Publicado em 1960, com o título de "Questão de Método" (Sartre, 1960/1987), o texto inicia pela indagação sobre a possibilidade de uma antropologia estrutural e histórica, passando em seguida a estabelecer relações entre o existencialismo e o marxismo. Isso, porque Sartre considera o existencialismo uma ideologia que vem à luz, precisamente, pela cegueira de alguns autores marxistas daquela época.

Assim sendo, o existencialismo sartreano se contrapõe àquilo que identifica como uma desumanização teórica: negando as abstrações originadas de leituras mecanicistas das obras de Marx, Sartre propõe um olhar compreensivo que vise o homem na concretude do vivido. Em vários momentos de seu texto, Sartre enfatiza que suas críticas se dirigem a alguns marxistas contemporâneos, e não aos escritos de Marx, ressaltando que seu existencialismo não rejeita os principais pressupostos marxianos. ${ }^{9}$ Sartre (1960/1987) defende que é preciso recuperar a irredutível singularidade do viver humano, enquanto constituída e constituinte das (contraditórias) relações sociais no/do modo de produção capitalista.

Aquilo que identificou como uma paralisia de alguns marxistas, bem como a cisão entre a prática e a teoria que observou no regime stalinista na URSS, trouxe para Sartre a desilusão. Com ela, o desejo de articular a perspectiva do materialismo histórico à abordagem do existencialismo. Recuperando Kierkegaard, na crítica que faz ao idealismo, quando destaca a impossibilidade de reduzir ou subsumir a experiência sentida no conhecimento, Sartre abre uma discussão interessante com um paradigma generalizante.

Sartre considera que alguns teóricos se colocam de forma abstrata porque suas análises, ainda que com o intuito de situar o objeto da investigação no contexto histórico amplo, na medida em que negam as minúcias, os traços que singularizam aquele objeto como "sendo ele mesmo e não um outro qualquer", acabam por esvaziar aquilo que pesquisam. Sartre seleciona alguns estudos de marxistas e do próprio Marx para sustentar essa afirmação, indicando que se o último buscava encontrar a pluralidade no objeto singular, os estudiosos mecanicistas explodem a particularidade.

Para Sartre, isso decorre da ausência de um olhar sintetizador, que unifique as significações que remetem $o$ objeto à totalidade (que o contém e que ele também engendra) e àquelas que dizem respeito a sua dimensão de "episódio único". É este duplo movimento, para o autor, que viabiliza apreender a verdade ${ }^{10}$ do objeto.

Portanto, Sartre recusa-se a abrir mão da historicidade radical proposta pelo marxismo. De modo semelhante, aferra-se à perspectiva dialética, concebendo a totalidade como engendrada justamente pelas contradições que encerra - que pelo seu movimento incessante, talvez seja mais adequado denominá-la "totalidade destotalizada" (1960/1987, p. 145).

Por outro lado, continua, se a parte exprime em si, a seu modo, a totalidade, seria igualmente uma abstração se fosse tomada fechada em si mesma, descolada do contexto que a sustenta. Seguindo o pensamento marxiano, a realidade concreta se constitui de mediações em diversos níveis: não se pode, por exemplo, limitar um dado acontecimento histórico ao princípio geral da luta de classes, sob pena de "saltar" sobre o processo que justamente configura o fenômeno desta forma e não de outra. Sartre (1960/ 1987) inclusive relembra Hegel para com ele advertir acerca da importância da forma: enquanto realidade que aparece, de alguma maneira materializa o real, sendo, portanto, necessário estudá-la. Cabe, então, buscar uma aproximação atenta ao objeto de investigação, deixando fora dela leis apriorísticas.

Tomando por base esta relação na qual os fenômenos são mutuamente constitutivos, Sartre (1960/1987) considera que se o plural está no singular e vice-versa, o estudo que focaliza um sujeito, por exemplo, um educador, aclara as relações entre educação e sociedade num dado tempo e espaço. Por seu turno, a pesquisa de leis gerais, como as políticas públicas existentes para a educação no contexto correspondente, aprofunda a reflexão sobre este educador (certamente único) objeto da investigação.

Ainda tratando da singularidade, Sartre (1960/1987) pontua as complexas relações entre um ato, a sua intenção, e aquilo que o sujeito imagina que faz, através da metáfora do ator. Este, ao interpretar uma personagem que dá alguns passos, não apenas caminha, mas imagina que é tal personagem; mesmo assim pisa no solo de um modo que o revela enquanto o sujeito-artista que é.

Sartre (1960/1987) aponta que não se pode esquecer, entretanto, que o sujeito, em seu agir, constitui o outro e é por ele constituído, de maneira que o produto de sua intervenção no mundo pode não corresponder totalmente 
àquilo que intenciona, àquilo que pensa estar fazendo, ou àquilo que espera como conseqüência do que faz. Todas essas dimensões, entretanto, se condensam de modo complexo na ação. A personagem que o ator interpreta, materializada, existe no mundo: estando sujeita ao estabelecimento de miríades de relações, supera aquilo que seu intérprete anteviu, sem por isso deixar de remeter ao processo criativo que a originou.

Logo, para Sartre (1960/1987), não se pode ligar de imediato numa análise histórica, por exemplo, o resultado de um acontecimento e o planejado por seus executores: o fazer humano se dá em meio às contradições que o regulam, e é aí que é preciso compreendê-lo. Esta concepção não visa desresponsabilizar o sujeito por aquilo que de fato faz, mas salientar que um ato (seja do corpo que dança, seja da boca que fala) pode estar relacionado a camadas de significações, que se conformam, podem se entrelaçar ou contradizer umas às outras. $\mathrm{O}$ ato, sem deixar de ser individual, é coletivo: exprime um grupo, mesmo que pelo veio da negação. Além disso, Sartre destaca que tais significações se hierarquizam, o que requer atenção especial do investigador.

Seguindo a compreensão das significações, Sartre (1960/ 1987) utiliza um exemplo no qual uma janela é aberta por alguém. $\mathrm{O}$ autor afirma que o movimento é inicialmente "progressivo", pois a trajetória do entendimento segue da origem para a explicação da configuração final. Podemos apreender a significação da ação de abrir a janela partindo do calor extremo que tomava o ambiente, antes que se fizesse algo.

Sartre (1960/1987) assegura que não há neste caso uma relação linear do tipo "estímulo-resposta”, pois é complexa a unificação entre pequenos movimentos que naquele processo se conformam, de uma determinada maneira, ao calor sentido (aquele que abre a janela pode fazê-lo de diversas formas, dependendo de suas condições e das características do objeto; poderia igualmente abanar-se).

Para a compreensão, ainda, é preciso que também o observador perceba a janela aberta por alguém como representante de uma necessidade de algo que antes não existia, a saber, a ventilação do espaço: o entendimento requer igualmente um percurso "regressivo". A compreensão da ação de abrir requer, portanto, que se possa vislumbrar "o antes e o depois", concebendo-a como parte de uma cadeia temporal. Isto é possível porque, num mundo humano, os objetos são transformados em signos. É somente num mundo humanizado que abrir uma janela em direção ao futuro faz sentido...

Este método proposto por Sartre, intitulado "progressivo-regressivo", é simultaneamente analítico e sintético. Como referência, Sartre destaca Lefebvre, considerando que a busca deste autor pelas "complexidades horizontais e verticais", bem como pelo condicionamento recíproco entre elas, possibilita ver o fenômeno em suas raízes mais gerais, sem por isso negar sua especificidade. Do método criado, Sartre faz questão de enfatizar que: "não se trata, aliás, de acrescentar um método ao marxismo: é o próprio desenvolvimento da filosofia dialética que deve levála a produzir num mesmo ato a síntese horizontal e a totalização em profundidade" (Sartre, 1960/1987, p. 147).

Sartre destaca que negar uma dada realidade (cuja formação remonta não apenas às determinações externas, mas também ao próprio sujeito enquanto passado já vivido) e superá-la, é precisamente o que define a ação humana como tal. Vê-se que a humanidade traz em seu bojo a carência, que a põe em movimento. É neste contexto, de negatividade em relação ao existente e positividade rumo ao ainda inexistente que Sartre define o projeto de ser (Sartre, 1943/1997).

O projeto de ser contempla as condições dadas e o campo dos possíveis que orienta a ação para um destino ou para outro. Ao que parece indeterminação, Sartre (1943/ 1997) afirma que, apesar da margem de ambigüidade daquilo "que ainda não chegou", este é fortemente marcado porque histórico. A dimensão do desejo, a expectativa pelo porvir, se constitui nesta tensão do (in)esperado. Esta espera em ação, embora singular, condensa em si também o plural: o sujeito pertence a um determinado contexto sócio-econômico, o que lhe viabiliza alguns caminhos em detrimento de outros. Mesmo aqueles que lhe são vedados, aparecem a ele na qualidade de ausência, de empobrecimento.

À guisa de exemplo, Sartre (1943/1997) explicita como a escolha profissional individual é atravessada pelas contradições sociais. Inversamente, as relações numa sociedade podem ser compreendidas também quando da análise das possibilidades de futuro profissional que ali se engendram. $\mathrm{O}$ projeto de ser, então, é formado por um movimento dialético entre a subjetivação e a objetivação, posto que o sujeito supera - seja pelo pensamento, seja pelo sentimento - o objetivo em prol de uma nova objetividade, a ser novamente subjetivada, num movimento incessante. Se a superação se materializa pela ação, o sujeito está permanentemente em direção a algo fora de si, o que autoriza pensar que, dentro do seu campo de possibilidades, ele escolhe. E em cada escolha, o sujeito está, em suas contradições, naquilo que recusa, conserva ou transforma.

A existência, nessa perspectiva, não é algo estanque, conteúdo interno sólido, mas contínua constituição em relação; se alguns temas se repetem numa vida, o fazem em outro nível de complexidade, porque quando retornam trazem não apenas o mesmo, mas também a inovação. A configuração desse existir capturada num momento pelo pesquisador, sintetiza os condicionamentos em cujo seio ela se formou. 


\section{Considerações Finais}

O texto vygotskiano de 1927 impressiona pela coerência entre forma e conteúdo. A perspectiva dialética, além de explicitada em palavras pelo autor, aparece em vários momentos da análise - por exemplo, na relação entre a disciplina geral e as particulares no campo científico. A abordagem mesma da ciência psicológica feita pelo autor segue direção semelhante: as propostas teóricas analisadas o são de forma que se possa perceber não apenas seus pontos falhos, mas aquilo que elas trazem como avanço no processo de conhecimento, num movimento de negação para a superação (Vygotski, 1927/1991).

A escrita de Vygotski, a exposição de suas idéias - o que igualmente se verifica no texto de Sartre - segue um caminho espiralado, pois os temas que são discutidos retornam num momento posterior, porém num outro nível de complexidade, seja pela introdução de novos conceitos, pelo estabelecimento de outras relações entre eles, ou pelo uso dos conceitos em algum exemplo específico.

É importante destacar os contextos nos quais cada autor empreendeu suas reflexões. Vygotski, em sua época, considerando que princípios explicativos sobre animais não dão conta da especificidade do humano, se propõe a humanizar a psicologia embasando-a na apropriação do método de Marx. Sartre, algumas décadas depois, discute com alguns marxistas a necessidade de se resgatar, em suas análises, o sujeito singular, dissolvido na coletividade.

Vale destacar que, para ambos, cada um a seu modo, a teoria precisa ter como alicerce uma proposta emancipatória, seja pelo estudo dos processos pelos quais o sujeito torna-se autônomo, capaz de regular a própria atividade (Vygotski, 1996), ou, como diz Sartre, pela assunção da responsabilidade de desvelar a complexidade histórica para os coletivos que a fazem (Sartre, 1960/1987). Em ambos os autores, a perspectiva histórica se apresenta de forma a, mais que rememorar/registrar o passado, clarificar o presente e vislumbrar possibilidades para futuro desenvolvimento das práticas e teorias. Esta perspectiva acerca da história e, como conseqüência, da temporalidade, vem apontando novas perspectivas metodológicas para a Psicologia Social, uma vez que destaca a necessidade de uma atenção mais pormenorizada na noção do porvir, indicando o passado como a base da inteligibilidade das ações dos sujeitos, mas enfatizando que o sentidos destas ações se encontra no futuro.

Sartre e Vygotski comungam ainda de uma visão do subjetivo que não o considera substância fechada e abstrata, pois concebem a subjetividade em relação ao objeto. Nas palavras de Vygotski (1996, p. 383), "como existência, o subjetivo é o resultado de dois processos, em si mesmos, objetivos." Sartre (1960/1987, p. 154), em perspectiva semelhante, afirma: "o projeto, como superação subjetiva da objetividade em direção à objetividade... O subjetivo aparece, então, como um momento necessário do processo objetivo."

Importante destacar que, naquele momento, discutindo com a Psicologia Espiritualista/Idealista de sua época, Vygotski enfatiza o momento explicativo da análise, bem como a busca de leis gerais a partir do estudo dos fenômenos particulares. Posteriormente, Sartre também questiona concepções abstratas/idealistas, porém agora presentes nos estudos de alguns marxistas de seu tempo, defendendo a retomada radical do papel da descrição e análise do fenômeno e sua singularidade.

Pode-se pensar ainda que Sartre, em 1960, teve condições de criticar concepções como a "dialética da natureza”, de Engels, por considerá-la extremamente mecanicista. Para o autor francês, a concepção de que a dialética na constituição do sujeito se sustenta na medida em que também a natureza é dialética, acaba caindo num veio metafísico: perde-se aí o processo ininterrupto por meio do qual os sujeitos (e não as rochas ou raios solares) existem ao passo em que se constroem diariamente, pondo-se a si mesmos em questão, fazendo a história que os constitui. O autor afirma que, a natureza ser ou não dialética, é um enigma que ainda não foi resolvido; o que é preciso ter clareza diz respeito à especificidade da história humana (Sartre, 1986).

Sem obliterar as diferenças entre as posições filosóficas de Vygotski e Sartre, considera-se que seus escritos podem embasar investigações sob a perspectiva do materialismo histórico e da dialética, no que se refere à análise do processo de como um sujeito chega a ser quem ele é. Dessa feita, ambos apresentam contribuições metodológicas importantes para a Psicologia Social, desenhando-se uma possibilidade de compreender tanto as significações que alguém atribui ao mundo, quanto de apreender, no sujeito, as múltiplas relações que o constituem.

Sob esta perspectiva, entende-se que a visão antropológica que os integra vem contribuir, a partir de alguns importantes detalhes metodológicos, com uma perspectiva materialista histórico-dialética que tem sido base na constante construção de uma Psicologia Social voltada para as transformações sociais em contextos culturais, econômicos e políticos específicos.

\section{Notas}

1 A fim de trazer para o texto a dimensão histórica dos escritos de Sartre e Vygotski, as referências a suas obras, quando citadas pela primeira vez, serão compostas pela data da primeira publicação, seguida do ano da edição utilizada para este trabalho.

Acesso em http://www.capes.gov.br

Acesso em http://www.scielo.br

4 Vale destacar também a dissertação de mestrado "Relações estéticas, criação e imaginação: A constituição do projeto de ser 
uma e outra, na dialética do ensinar e do aprender", defendida por França no ano de 2006, que por isso ainda não consta nos registros.

5 O conceito de consciência se revela como uma das diferenças teóricas entre Vygotski e Sartre, mas a complexidade como esta questão merece ser abordada não compatibiliza com os propósitos deste artigo. O objeto central deste artigo é apontar as semelhanças e possíveis articulações destes dois autores no campo metodológico. Não obstante, no que se refere a estes dois autores, um outro artigo acerca do conceito de consciência merece ser produzido.

6 Nesse seu texto, Vygotski (1996) utiliza este termo para referir-se, fundamentalmente, à vertente introspeccionista daquele tempo.

7 A fim de delimitar aquilo que concebe como uma crise na Psicologia, Vygotski utiliza este termo para designar profissionais como psicotécnicos, comprometidos de forma direta com intervenções concretas na realidade.

8 Segundo Delari Jr. (2000, p. 62), é preciso compreender a consciência em Vygotski como tratando do "ser humano consciente", visto que não há consciência como coisa ou instância interna. Inversamente, a consciência se faz processo, porque se forma a partir das/nas relações sociais, pela via da apropriação, conservando da comunicação com o outro, a dialogicidade e mediação semiótica, que a configuram como "quase-social” (Vygotski, 2000, p. 151).

9 Sartre afirma, reiteradas vezes, suas críticas aos autores marxistas, e não às elaborações do próprio Marx.

10 Sobre este conceito, Sartre afirma: "Para nós a verdade torna-se, ela é e será devinda. É uma totalização que se totaliza sem cessar; os fatos particulares nada significam, não são nem verdadeiros nem falsos enquanto não forem referidos pela mediação de diferentes totalidades parciais à totalização em curso." (1960/1987, p. 124, itálicos do autor).

\section{Referências}

Delari, A., Jr. (2000). Consciência e linguagem em Vigotski: Aproximações ao debate sobre a subjetividade. Dissertação de Mestrado não-publicada, Universidade Estadual de Campinas, Programa de Pós-Graduação em Educação, Campinas, SP.

França, K. (2006). Relações estéticas, criação e imaginação: A constituição do projeto de ser uma e outra, na dialética do ensinar e aprender. Dissertação de Mestrado não-publicada, Universidade Federal de Santa Catarina, Programa de Pós-Graduação em Psicologia, Florianópolis, SC.

Maheirie, K. (2001). Sete mares numa ilha: A mediação do trabalho acústico na construção da identidade coletiva. Tese de Doutorado não-publicada, Pontifícia Universidade Católica de São Paulo, Programa de Pós-Graduação em Psicologia Social, SP.

Maheirie, K. (2003). Processo de criação no fazer musical: Uma objetivação da subjetividade, a partir dos trabalhos de Sartre e Vygotsky. Psicologia em Estudo, 8(2), 147-153.

Oliveira, M. (1998). Lembranças do passado: A infância e a adolescência na vida dos escritores brasileiros. 1998. Tese de Douto- rado não-publicada, Universidade de São Paulo, Programa de Pós-Graduação em Psicologia Escolar e do Desenvolvimento Humano, SP.

Oliveira, P. (2004). Literatura: Transição ecológica para aquisição de resiliência. 2004. Dissertação de Mestrado não-publicada, Pontifícia Universidade Católica do Rio Grande do Sul, Programa de Pós-Graduação em Lingüística e Letras Porto Alegre, RS.

Sartre, J-P. (1986). Sartre no Brasil: A Conferência de Araraquara: Filosofia marxista e ideologia existencialista. São Paulo, SP: Editora da Universidade Estadual Paulista.

Sartre, J-P. (1987). Questão de método. In J-P. Sartre. Sartre - Vida e obra (pp. 111-191). São Paulo, SP: Nova Cultural.

Sartre, J-P. (1997). O ser e o nada: Ensaio de Ontologia fenomenológica (5. ed.). Petrópolis, RJ: Vozes.

Vygotski, L. S. (1991). El significado histórico de la crisis de la psicología. Una investigación metodológica. In Obras escogidas: Vol. 1 (pp. 257-407). Madrid, España: Visor. (Original publicado em 1927)

Vygotski, L. S. (1995). Método de investigación. In Obras escogidas: Vol. 3 (pp. 47-96). Madrid, España: Visor. (Original publicado em 1931)

Vygotski, L. S. (1996). Teoria e método em Psicologia. São Paulo, SP: Martins Fontes.

Vygotski, L. S.(1998). Psicologia da arte. São Paulo, SP: Martins Fontes. (Original publicado em 1925)

Vygotski, L. S. (2000). Obras Escogidas: Vol. 3. Madrid, España: Visor.

Vygotski, L. S. (2001). Psicologia pedagógica. São Paulo, SP: Martins Fontes. (Original publicado em 1926)

Kátia Maheirie é psicóloga, doutora em Psicologia Social. Professora do Programa de Pós-Graduação em Psicologia da Universidade Federal de Santa Catarina - UFSC. Endereço para correspondência: UFSC/Centro de Filosofia e Ciências Humanas/ Pós-Graduação em Psicologia/Campus Universitário Trindade - Florianópolis - SC. CEP 88010-970. maheirie@cfh.ufsc.br

Kelly Bedin França é psicóloga, mestre em Psicologia.

\section{Vygotski e Sartre: Aproximando Concepções Metodológicas na Construção do Saber Psicológico}

Kátia Maheirie e Kelly Bedin França

Recebido: 26/04/2006

$1^{a}$ revisão: 20/11/2006

Aceite final: 26/12/2006 